\title{
Determinants of Intention to Purchase Chicken in Italy: The Role of Consumer Risk Perception and Trust in Dif- ferent Information Sources*
}

\author{
Gianluca Stefani**, Alessio Cavicchi and Donato Romano \\ Department of Agricultural and Resource Economics, University of Florence, \\ P.le delle Cascine 18, 50144 Firenze, Italy \\ $*$
}

Abstract:

The aim of this paper is to explain how purchasing intentions are influenced by different level of risk perception and trust in food safety information investigating the determinants of chicken purchase among a sample of Italian consumers. The assessment of determinants of intention to purchase was carried out estimating a causal model in which attitudes, perceived behavioural control and perceived risk play a major role in determining buyer's behaviour. A second model that links risk perception to a number of constructs was estimated. In particular the role of trust was highlighted either as a general construct or as specific constructs targeting food chain, policy actors and media.

Keywords: trust, food risk, risk perception, information

JEL classification: C31, D12, D80

\footnotetext{
${ }^{*}$ Research supported by the EU Commission, Quality of Life Programme, Key Action 1 (Food, Nutrition and Health): "TRUST - Food risk Communication and Consumers' Trust in the Food Supply Chain" (QLK1-CT-2002-02343).

** Corresponding author: gstefani@unifi.it.
} 


\title{
Determinants of Intention to Purchase Chicken in Italy: The Role of Consumer Risk Perception and Trust in Different Information Sources
}

\author{
Gianluca Stefani, Alessio Cavicchi and Donato Romano
}

\section{Introduction}

The aim of this paper is to explain how purchasing intentions are influenced by different level of risk perception and trust in food safety information investigating the determinants of chicken purchase among a sample of Italian consumers. Risk perception plays a crucial role in the appreciation of the level of food safety and the "probability of not suffering some hazard from consuming the food in question" (Brunso et al., 2002) is a strong determinant of food consumption choice. Chicken was chosen for two reasons: firstly it is a widely consumed product and usually not associated with high risks ${ }^{1}$ and secondly because chicken consumption is not as sensitive to food safety concerns as beef after BSE crisis. Hence the results of this research could shed some lights on how way risk perception interacts with other attitudes and affects behaviour in a "normal" context and in relation to a familiar, quite popular foodstuff.

The assessment of determinants of intention to purchase was carried out estimating a causal model in which attitudes, perceived behavioural control and perceived risk play a major role in determining buyer's behaviour. A second model that links risk perception to a number of constructs was estimated. In particular the role of trust was highlighted either as a general construct or as specific constructs targeting food chain, policy actors and media.

The structure of the paper is quite straightforward: section 2 presents the theoretical background of the modelling effort, while section 3 provides some information on methodological issues and section 4 discusses the main results of the econometric estimates. Finally, section 5 summarizes the main findings of the research.

\section{Trust, Risk Perception, and Attitude to Purchase}

The starting point for the modelling effort carried out in this research is the so-called "SPARTA" model" developed by Mazzocchi et al. (2004) within the TRUST project. As an extension of the Theory of Planned Behavior ${ }^{3}$ (TPB, Ajzen, 1991), the SPARTA model links the concept of trust in information to the categories of attitude, subjective norm and perceived risk. TPB is a useful tool for understanding the individual behaviour in a wide range of contexts: from smoking and drinking, to the use of contraceptives, to food consumption where TPB has been often associated with the estimation of structural equation models (McEachern and Schroder, 2004; Pierro et al., 2003; Shaw and Shiu, 2002; Bredahl, 2000).

\footnotetext{
${ }^{1}$ Although chicken has been recently affected by a number of different food scares ranging from dioxin contamination through salmonella outbreaks to chicken flu, when the survey took place (year 2004) no major safety issue was in place. ${ }^{2}$ The acronym SPARTA comes from the initials of the global variables used to explain behavioral intentions: Subjective Norm (S), Perceived Behavioral Control (P), Attitudes (A), Risk perception (R), Trust (T), and Alia (Al) i.e. other variables like socio-demographics.

${ }^{3}$ Which is in turn a development of the "Theory of Reasoned Action" originally proposed by Ajzen and Fishbein (1980).
} 


\subsection{The Intention to Purchase Model}

According to TPB, intentions to behave can be predicted from attitudes toward the behaviour (the beliefs related to the outcomes we expect from a certain behaviour), subjective norms (others' normative beliefs and their expectations about our beliefs) and perceived behavioural control (the perception of the existence of some factors able to influence a performance of the behaviour). The SPARTA model introduces two more important variables for the purpose of our research: perceived risk of eating chicken and a variable related to trust in information about chicken safety (Figure 1).

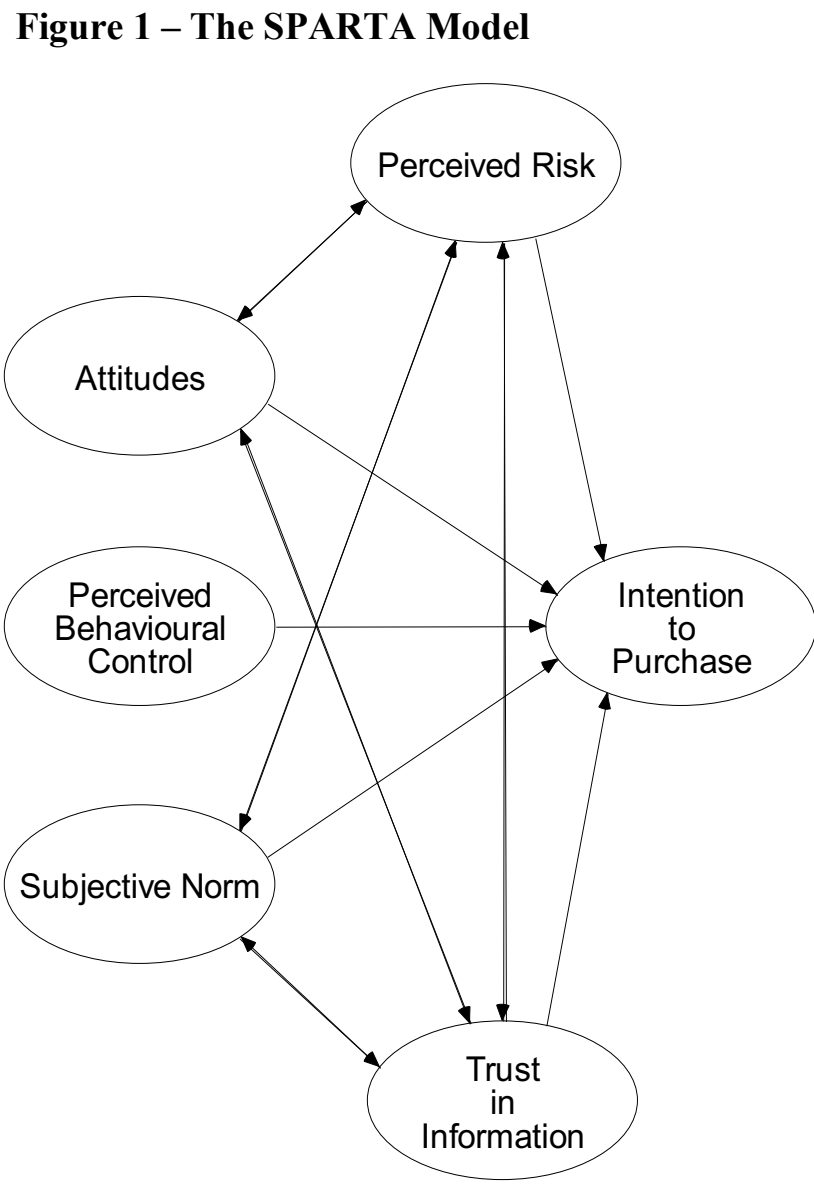

In this research, some modifications to the original SPARTA model have been devised. First of all, the variable trust in information is considered only in the risk perception model (see section 2.2) as a determinant of perceived risk. Moreover the latent variable represented by the subjective norm has been dropped out. In fact subjective norm is a concept based on how one "should" act in response to the views or thoughts of others ${ }^{4}$ and it seems to be more explanatory in the case of smoking or drinking rather than in the field of chicken consumption. Anyway, including this variable in our model didn't lead to a better fit. Thus, the model adopted in our research can be represented as in Figure 2.

\footnotetext{
${ }^{4}$ Others including friends, family members, colleagues, etc.
} 


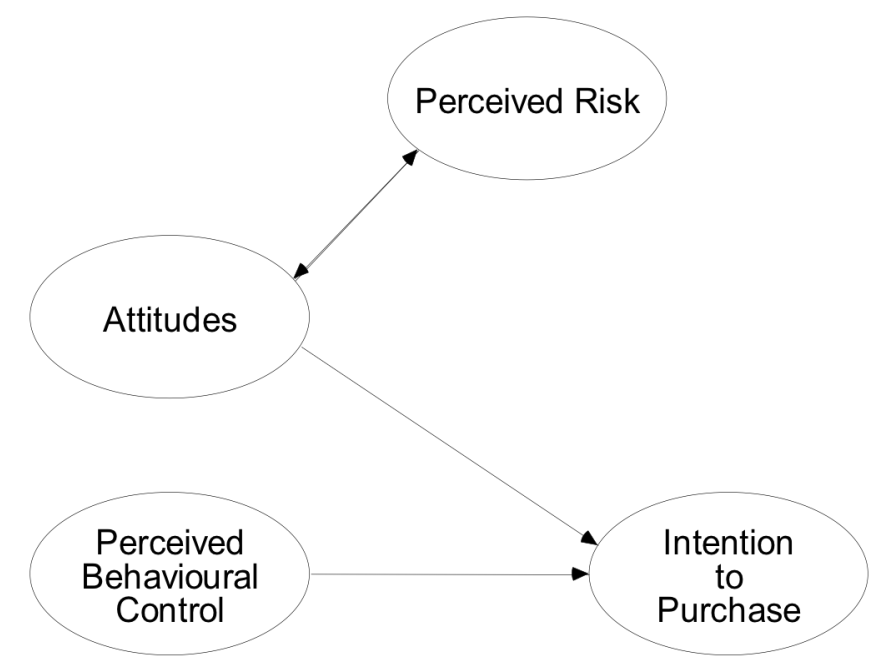

\subsection{The Risk Perception Model}

Perceived product-related risks represent one set of beliefs that in turn determines attitudes towards products. In this context risk perception is framed as the risk to the respondent him- or herself rather than as risk to people in general (Sjoberg, 1999b). The proposed model assumes that perceived risk in turn is influenced by trust in information sources, trust in food chain and policy actors, risk knowledge and a measure of quality consciousness (Figure 3).

Trust affects risk perceptions both directly when related to risk management institutions (known as social trust) and indirectly as determinants of confidence in risk information when related to information sources (interpersonal trust). The latter "relates to the perceived presence or absence of particular traits in the source, describing much of the research on source credibility" (Viklund, 2003). A valid relationship between trust in information source and risk attitude change has not generally been supported by empirical work but for lifestyle hazard (such as food contamination) evidences are more encouraging.

Social trust is "the willingness to rely on those who have the responsibility for making decisions and taking actions related to the management of realms of public health and safety" (Siegrist et al., 2000). Trust has a clear function as it "reduces the complexity people are faced with. In other words, instead of making rational judgements based on knowledge, social trust is employed to select experts who are trustworthy and whose opinions can be believed as being accurate" (Siegrist and Cvetkovich, 2000). Therefore, trust in food chain actors and in other policy actors can be considered a form of social trust to be modelled separately from trust in information media (closer to the concept of interpersonal trust).

Usually two different forms of social trust can be identified, specific trust and general trust. The former refers to trust specifically related to a given referent (for example the food industry, or the national food safety authority) or to a given hazard. Value similarity, that is the extent to which salient values are similar across perceivers and people being judged (risk managers), seems to be strongly related to specific trust (Siegrist et al., 2000). Conversely, general trust is not related to any specific hazard or risk manager. It can be defined as "the belief that most people are trustworthy most of the time" (Siegrist et al., 2003 referent). Sjoberg (1999b) finds that even if specific trust shows more explicative power with respect to general trust in explaining risk perceptions the latter shows a significant impact altogether. 
Besides interpersonal and social trust another factor that affects risk perception is knowledge about the hazard that respondents self-assess. Siegrist and Cvetkovich (2000) discuss results of a study where trust in public authorities better explain risk perception when hazard related knowledge is lacking.

Finally, food quality consciousness (Steenkamp, 1989) is assumed to negatively affect risk perception hypothesizing the existence of a trade-off between quality and safety. Indeed, this appear to hold for foodstuff such as cheese from non pasteurized milk and other regional speciality foods. This might be related to what Buhr et al. (1993) observed for irradiated food that were considered either safer or more artificial at the same time.

\section{Figure 3 - The Risk Perception Model}

\section{Methodology}

\subsection{The Survey}

A questionnaire structured in three different sections was realized to collect data that feed into the SPARTA model. The first section focussed on understanding food consumption habits, investigating specifically likes and dislikes and attitudes towards chicken meat. The second section was about lifestyles patterns, trust feeling towards several actors in the food supply chain and risk perception for human health. The final section focussed on socio-demographic information.

After a first phase characterized by the validation of the questionnaire through a pilot study, the final survey was conducted in Italy during Spring 2004, yielding 580 valid face-to-face interviews 5 adopting the paper-and-pencil method ${ }^{6}$. The locations were randomly distributed across the country and stratified according to socio-demographics in order to have a statistically representative sample. An incentive of 25 euro per interview was given to each respondent.

\subsection{Data Analysis}

Data analysis was carried out using SPSS $\subset$ v. 12.0.1 and Amos $\bigodot$ a program that implements the general approach to data analysis known as Structural Equation Modelling (SEM). The basic assumption of SEM is that exists a causal structure among a set of latent unmeasured variables whilst the observed variables are directly related to the first set of variables. In order to graphically represent a SEM it is possible to use a number of acceptable conventions ${ }^{7}$ (Maruyama, 1998).

Maximum Likelihood (ML) was used to estimate the SEM parameters: Ulmann (2001) argues that the ML is a good tool for medium-large samples, while Hoogland and Boomsma (1998) acknowledge that this method shows fairly robust to moderate violations of normality.

The presence of missing data requests a further discussion. In fact, there are three different methods commonly used for dealing with incomplete data: "listwise deletion" (the elimination of the entire case when a single value is missed), "pairwise deletion" (the exclusion of an observation from the calculation only when it is missing a value that is needed for the computation of that par-

\footnotetext{
${ }^{5}$ With reference to the sample size, it should be stressed that 580 cases represents a more than satisfactory number of observations to perform a structural equation modeling analysis: in fact it is commonly acknowledged that 300 cases would be sufficient (Comrey and Lee, 1992; Ullman, 2001).

${ }^{6}$ This typology of interview is appropriate for long questionnaires (in our case 62 questions) and assures an higher quality response comparing with other techniques (i.e. mail and telephone) while reducing the non-response ratio.

${ }^{7}$ Usually, observed variables are displayed as boxes whilst unobserved (latent) variables are drawn as circles. These two kinds of figures are connected through arrows explaining relationships among causal variables and effects: in presence of a double-headed arrow we assume that variables are correlated with each other whilst the single-headed arrow indicates the direct influence of a latent variable via a regression-type relationship
} 
ticular moment) and "data imputation" (the replacement of missing values with some kind of guess, for example a mean value). Amos@ does not rely on any of these methods: it computes full information maximum likelihood on the hypothesis that data are missing at random, that is missingness and data values are statistically unrelated.

For the evaluation of the model fitting we used both the chi-square and the root mean square error of approximation (RMSEA) statistics. The first one is sensitive to sample size and in our case it doesn't seem really appropriate to evaluate the model. Thus, following a common approach RMSEA was used to measure the goodness of fit and a value of 0.80 was adopted as threshold for the goodness of fit according to the common standard (Browne and Cudeck, 1993).

\section{Results}

\subsection{Description of Constructs}

Global attitude towards buying chicken for one's own household

In the original Fishbein's multi-attribute model and subsequent TPB extension global variable such as overall attitude towards performing a specific behaviour are regressed or correlated with summation variables that in turn are given by the summation of belief strengths weighted by their evaluations (such as in term of outcomes etc.). In the same vein of Bredahl et al. (1998), a different approach was adopted here by empirically retrieving weights through standardized regression coefficients of global variables on beliefs. On their turn both global variables and beliefs are conceived either as single items or underlying latent factors.

Global attitude towards buying chicken for one's own household was measured by four semantic differentials, namely good-bad, disagreeable-agreeable, convenient-inconvenient, ethicalunethical. Seven point scales were employed through all questionnaire items. To assess inter-item reliability the Cronbach alpha value was computed after reversing the score of the second item (i.e. buying chicken is disagreeable/agreeable). The alpha value of 0.81 is acceptable as it is above the 0.70 threshold figure suggested by Hair et al. (1998). Factor structure of the global attitude was explored performing a principal component analysis. All items but the second show positive loadings on the first component that accounts for about $65 \%$ of the variance. Hence unidimensionality of the items was retained for the SEM model.

\section{$\underline{\text { Attitude beliefs }}$}

Respondents were asked to express their valuation through a 7-point Likert scale on 12 items related to attitude beliefs toward chicken. As beliefs regard a range of issues from animal welfare to taste, factor structure was investigated performing a principal component analysis with factor rotation (varimax method) to look for the presence of latent variables (Table 1).

Table 1 - Factor Structures of Attitude Beliefs

\begin{tabular}{lcccc}
\hline \multicolumn{1}{c}{ Items - Factor labels } & Taste & Ethics & Safety & Convenience \\
\hline Chicken tastes good & $\mathbf{0 . 7 5}$ & 0.06 & 0.05 & -0.25 \\
Chicken is good value for money & $\mathbf{0 . 5 6}$ & -0.03 & 0.25 & 0.13 \\
Chicken is not easy to prepare & -0.06 & 0.08 & -0.13 & $\mathbf{0 . 8 2}$ \\
Chicken is a safe food & $\mathbf{0 . 6 3}$ & 0.00 & 0.13 & 0.49 \\
All the family likes chicken & $\mathbf{0 . 7 5}$ & 0.05 & 0.21 & 0.06 \\
Chicken works well with lots of other ingredients & $\mathbf{0 . 6 0}$ & -0.10 & 0.42 & -0.02 \\
Chicken is low in fat & 0.13 & 0.05 & $\mathbf{0 . 8 7}$ & -0.06 \\
Chicken is low in cholesterol & 0.10 & 0.07 & $\mathbf{0 . 8 6}$ & -0.02 \\
Chicken lacks flavour & $\mathbf{- 0 . 5 7}$ & 0.15 & 0.15 & 0.42 \\
Buying chicken helps the local farmers and economy & 0.31 & $\mathbf{0 . 5 1}$ & 0.28 & 0.21 \\
I do not like the idea of killing chickens & -0.04 & $\mathbf{0 . 8 7}$ & 0.02 & 0.13 \\
Chicken is not produced taking into account animal welfare & -0.01 & $\mathbf{0 . 8 8}$ & 0.05 & -0.05
\end{tabular}


Four main dimensions seem to emerge from the analysis related to taste and value, ethical concerns, safety attributes and convenience dimension. The fourth dimension was dropped from the analysis since it accounts for $10 \%$ of the variance only. The other three dimensions were retained as latent variables in the SEM modelling exercise including only single items that show a loading value higher than 0.50 (in bold in Table 1).

\section{$\underline{\text { Risk beliefs }}$}

Risk beliefs were elicited through two separate battery of questions. In the first group of questions, the respondents was asked to rate the risk any person in the interviewee household would suffer from a list of morbidity factors as a result of eating chicken (e.g. Salmonella, Escherichia, etc.), while in the second the risk rating was referred to long-term health problems due to eating chicken (e.g. cholesterol, growth hormones, etc.). A principal component analysis was performed to check for the presence of different dimensions in risk perception related to short term and long term health problems (Table 2).

Table 2 - Factor Structure of Risk Beliefs

\begin{tabular}{lcc}
\hline \multicolumn{1}{c}{ Risk Factors } & Global & Short-term \\
\hline E. coli & 0.14 & $\mathbf{0 . 9 0}$ \\
Salmonella & $\mathbf{0 . 5 1}$ & $\mathbf{0 . 6 7}$ \\
Listeria & 0.12 & $\mathbf{0 . 9 1}$ \\
Allergy from food additives & $\mathbf{0 . 6 1}$ & $\mathbf{0 . 5 7}$ \\
Cholesterol & $\mathbf{0 . 5 2}$ & 0.48 \\
Health problems from pesticides & $\mathbf{0 . 7 9}$ & 0.35 \\
Health problems from antibiotics & $\mathbf{0 . 9 0}$ & 0.20 \\
Health problems from growth hormones & $\mathbf{0 . 9 0}$ & 0.11 \\
Chicken flu & $\mathbf{0 . 8 4}$ & 0.15 \\
\hline Explained variance & $43 \%$ & $32 \%$ \\
\hline
\end{tabular}

The analysis shows there is no clear division between long-term and short-term risk factors. Rather, the first component can be interpreted as global concern for all long-term risk factor, for Salmonella and for allergies from additives. Conversely, the second factor refers to short-term morbidity causes only. These findings are confirmed by the Cronbach alpha values for all items that is higher than 0.90. The only two items that show lower correlation with the summation variable are the first and the third. Therefore, in order to have a global measure of risk perception related to eating chicken, only the items with loading higher than 0.50 to the first component were considered as manifest variables in the SEM exercise.

\section{Perceived behavioural control}

Intention to purchase was specified with reference to a specific time framing ("next week") and to one of the factors that may impact the intention to purchase, i.e. the presence of stored chicken in the freezer or the recent consumption of too much chicken. The items used to assess this control variables were "I typically store chicken in my freezer" and "We eat too much chicken". A 7-point scale anchored to completely disagree and completely agree was used in this case. The outcome evaluation was given by the following items:

- "Let's say you do have some chicken in your freezer. It is likely you would buy more next week?",

- "Let's say last week you ate a lot of chicken. Is it likely you would not buy chicken at all next week?". 
For these items the scale was anchored to "Extremely unlikely" and "Extremely likely". Two variables were computed multiplying these control beliefs for their respective outcome beliefs and used as manifest variables linked to a latent PCB construct.

\section{Subjective norm}

Three items were devoted to subjective norm measurement. The first two were motivation to comply items whether the third one measured the expectation of approval. However including a global variable on subjective norm neither improved the fit of the intention to purchase model, nor showed any significant impact on intention to purchase. Therefore, it was not included in any further analysis.

\section{Intention to purchase}

Intention to purchase was measured by the following single item: "How likely or unlikely is that you will buy fresh or frozen chicken for your household's home consumption at least once in the next week?". In this case also, answers were collected through a 7-point scale anchored to "extremely unlikely" and "extremely likely".

\section{$\underline{\text { General trust }}$}

A measure of general trust was based on the following four items proposed by Siegrist et al. (2003) and evaluated on a 7-point Likert scale:

- "If given a chance, most people would try to take advantage of you",

- "Most people are too busy looking out for themselves to be helpful",

- "You can't trust strangers anymore",

- "I never rely on other people".

A Cronbach's alpha of about 0.79 shows a satisfactory inter-item reliability. Factor structure was explored performing a principal component analysis. All items show positive loadings higher than 0.68 on the first component that accounts for about $62 \%$ of the variance. Hence unidimensionality of the latent construct general trust is assumed.

\section{$\underline{\text { Risk knowledge }}$}

Knowledge of possible risk from eating chicken was elicited asking respondents to indicate their degree of knowledge (through a 7-point scale from "not at all knowledgeable" to "extremely knowledgeable") with respect to the same eight risk factors used to assess risk beliefs. As in the risk belief case, factor structure was preliminary investigated. The outcome was quite similar to what was found in the case of risk beliefs (Table 3) with knowledge of Salmonella, allergy from additives and long term risk factors loading on the first factor, while knowledge of E. coli and Listeria loading on a second factor. In order to have a measure of risk knowledge consistent with that used for risk beliefs only the item that show a loading higher than 0.5 on the first factor were used as manifest variable for a risk knowledge construct to use in the SEM exercise.

Table 3 - Factor Structure of Risk Knowledge

\begin{tabular}{|c|c|c|}
\hline Risk Factors & Global & Short term \\
\hline E. coli & 0.20 & 0.90 \\
\hline Salmonella & 0.58 & 0.51 \\
\hline Listeria & 0.14 & 0.91 \\
\hline Allergy from food additives & 0.71 & 0.34 \\
\hline Cholesterol & 0.82 & 0.23 \\
\hline
\end{tabular}




\begin{tabular}{lll} 
Health problems from pesticides & $\mathbf{0 . 9 0}$ & 0.18 \\
Health problems from antibiotics & $\mathbf{0 . 9 1}$ & 0.19 \\
Health problems from growth hormones & $\mathbf{0 . 9 1}$ & 0.18 \\
Chicken flu & $\mathbf{0 . 8 3}$ & 0.15 \\
\hline Explained variance & $52 \%$ & $24 \%$ \\
\hline
\end{tabular}

Food quality consciousness

Food quality consciousness was measured trough the following five items adapted from Steenkamp (1989) using a 7-point Likert scale:

- "I like to purchase the best quality food I can afford",

- "I usually aim to eat natural foods",

- "I am willing to pay more for a better quality product",

- "Quality is decisive for me when purchasing foods",

- "I always aim for the best quality".

The construct shows a good degree of inter-item reliability (Cronbach's alpha is 0.88 ) while principal component analysis points out that $63 \%$ of the variance can be explained by the first factor. All items have positive loadings higher than 0.65 .

Trust in food chain and policy actors and in information media

Trust in information sources was elicited asking respondent to answer at the following question: "Suppose that each of the following has provided information about potential risks associated with salmonella in food. Please indicate to what extent you would trust that information" with respect to a list of chain actors, policy actors and information media. Factor structure was investigated separately for media and chain/policy actors. Trust in media can be modelled as a bidimensional construct as the principal component analysis suggests the presence of two factors (Table 4), the first one gathering together the main media (such as TV news, Newspaper, Tv adverts) while the second factor relating to other media such as radio, magazines and internet. Noticeably, product label appears to stand alone having low loading on each of the first two factors. For this reason it was dropped from the analysis. 
Table 4 - Trust in Media

\begin{tabular}{lcc}
\hline & Main media & Other media \\
\hline Television documentary & $\mathbf{0 . 8 3}$ & 0.16 \\
Television news / current affairs & $\mathbf{0 . 8 5}$ & 0.20 \\
Television adverts & $\mathbf{0 . 6 9}$ & 0.25 \\
Newspapers & $\mathbf{0 . 6 2}$ & 0.42 \\
Internet & 0.11 & $\mathbf{0 . 7 7}$ \\
Radio & 0.29 & $\mathbf{0 . 7 7}$ \\
Magazines & 0.28 & $\mathbf{0 . 7 8}$ \\
Product label & 0.24 & 0.49 \\
\hline Explained variance & $31 \%$ & $29 \%$ \\
\hline
\end{tabular}

Conversely, trust in chain actors or in policy actors has a more complex factor structure. As it is illustrated by Table 5, the first four factor accounts for $67 \%$ of the variance. The first factor gathers together information sources that could be labelled as independent or expert-based ranging from food safety authorities to consumer organisation. The second factor clearly relates to food chain actors from farmers to retailers while the other two factors describe environmental-ethical concerned and traditional policy actors, respectively. Considering that the impact on risk perception of trust in alternative (i.e. environmental-ethical concerned) information sources is trivially negative, and that the opposite relationship is expected in relation to trust in traditional policy actors, only the first two components were used in the SEM exercise, in order to keep the model complexity to a manageable size.

Table 5 - Trust in Food Chain and Policy Actors

\begin{tabular}{lcccc}
\hline & Independent & Chain & Green & Policy \\
\hline Shopkeepers & 0.05 & $\mathbf{0 . 8 0}$ & -0.05 & 0.13 \\
Supermarkets & 0.17 & $\mathbf{0 . 7 6}$ & -0.11 & 0.22 \\
Organic shop & 0.15 & $\mathbf{0 . 6 5}$ & 0.30 & -0.08 \\
Specialty store & -0.08 & $\mathbf{0 . 7 2}$ & 0.26 & 0.22 \\
Farmers / breeders & 0.18 & $\mathbf{0 . 7 0}$ & 0.15 & -0.11 \\
Processors & 0.24 & $\mathbf{0 . 6 1}$ & 0.04 & 0.25 \\
Doctors / health authority & $\mathbf{0 . 7 9}$ & 0.24 & 0.15 & -0.03 \\
University scientists & $\mathbf{0 . 7 3}$ & 0.19 & 0.14 & 0.07 \\
National authority in charge of food safety & $\mathbf{0 . 6 9}$ & 0.03 & 0.12 & 0.44 \\
Government & 0.34 & 0.11 & 0.20 & $\mathbf{0 . 8 0}$ \\
Political groups & -0.01 & 0.20 & 0.27 & $\mathbf{0 . 8 2}$ \\
Environmental organisations & 0.22 & 0.06 & $\mathbf{0 . 8 6}$ & 0.24 \\
Animal welfare organisations & 0.15 & 0.07 & $\mathbf{0 . 8 9}$ & 0.16 \\
Consumer organisations & $\mathbf{0 . 6 5}$ & 0.04 & 0.43 & 0.14 \\
European Union authority in charge of food safety & $\mathbf{0 . 6 3}$ & -0.04 & 0.25 & 0.40 \\
\hline Explained variance & $19 \%$ & $21 \%$ & $14 \%$ & $13 \%$ \\
\hline
\end{tabular}

\subsection{Sample Characteristics and Descriptive Results}

The sample is characterized by an equilibrium between females and males (51\% versus $49 \%)$ while there is a prevalence of married people (58.6\%), persons living in town of more than 10.0000 but under 100.000 inhabitants $(61.6 \%)$ and households without kids $(67.1 \%)$. Only a little percentage of the respondents belongs to consumer or environmental organization $(3.4 \%)$. The other demographic characteristics seem to be well balanced compared with statistics at country level.

The analysis of purchasing habits reveals that on average the respondents buy food for their household's home consumption every week; instead not every week they buy chicken but it is evident that that fresh chicken is the preferred one. On average, families buy one kilo of chicken 
spending more than 8 euro, while the favourite kind of chicken is the "standard" one. Moreover, the favourite shops for buying chicken meat are supermarkets and butchers, while it is given for granted that discount supermarkets are not trustable at all.

Finally, with regards to quality the respondents perceive with good evidence that chicken has several good properties: it tastes good and it is a healthy food with low contents of cholesterol and fat but, despite the fact that it is good value for money, it is not easy to prepare. On the other hand, chicken is felt as a menace for health because of the belief that growth hormones and antibiotics are used to breed it. However, comparing it with other sources of risk, eating chicken is not perceived as much dangerous as smoking cigarettes or assuming illegal drugs. The perception of safe chicken is related to a fresh, clearly labelled one and preferably produced in the country of origin with free range breeding method.

\subsection{Structural Equation Modelling: The Intention to Purchase Model}

The results of the estimation of the intention to purchase model highlight that all the correlations are significant at least at the 5\% probability level, except for the impact of chicken welfare concerns on attitude to purchase and of the direct impact of perceived behavioural control on intention to purchase (Table 6).

Figure 4 - Intention to Purchase Model Path

The intention to purchase is significantly influenced by attitudes to purchase (0.178). This parameter shows the expected positive sign, that is a high attitude to buy chicken positively influences the intention to buy chicken next week. In turn, attitude is determined by previous experiences of taste and risk. These two variables also show the expected signs. For instance, the experience of a long term health problem due to eating chicken in respondent's family implies a negative attitude to buy chicken. Moreover, if the respondent and his family like chicken for any reasons (flavour, texture and cooking performance, etc.) the attitude to purchase is stronger (0.839). The evaluation of the model fitness through Chi-square and RMSEA statistics provide reasonable results: 1,071.33 and 0.81 .

Table 6 - "Intention to Purchase Model" Path Estimates

\begin{tabular}{ccccccc}
\hline & & & Estimate & S.E. & C.R. & P \\
\hline attitude & $\leftarrow$ & risk & -.177 & .067 & 2.655 & .008 \\
attitude & $\leftarrow$ & taste & .839 & .075 & -11.186 & $* * *$ \\
attitude & $\leftarrow$ concern & -.008 & .068 & .124 & .902 \\
intention to purchase & $\leftarrow$ attitude & .178 & .052 & -3.422 & $* * *$ \\
intention to purchase & $\leftarrow$ & PBC & -.066 & .093 & -.714 & .475 \\
\hline
\end{tabular}

\subsection{Structural Equation Modelling: The Risk Perception Model}

Results from the risk perception model suggest that trust has a negative impact on risk perception with the sole exception of trust in main media that shows a positive (albeit not significant at the 0.05 level) impact.

\section{Figure 5 - "Risk Perception Model" Path}


Interestingly, while trust in other media, such as radio and internet seems to negatively impact on risk, trust in TV and newspaper doesn't seem to have a significant impact. Perhaps other sociological factors underlie this pattern of relationships. Probably it should be taken into account the current situation of absence of free competition in the Italian TV sector that possibly undermines the reliability of this source for an important share of consumers. Measures of trust in actors (food chain actors and experts or independent actors) that are comparable to social trust measures seem to be affected by the generic measure of trust in others confirming the findings of other studies (Siegrist et $a l ., 2003)$. Knowledge of risk shows a positive impact on risk perception. However this result should be interpreted cautiously as risk perception measures have been built from answers to a series of items related to specific risk factors whose knowledge is a prerequisite to appreciate risk. Finally, quality consciousness shows a negative impact on risk supporting the role of safety as a key component of overall quality rather than the perception of a trade-off between quality and safety. This is probably related to the plain nature of chicken as ordinary food.

Tab 7 - "Risk Perception Model" Path Estimates

\begin{tabular}{ccccccc}
\hline & & & Estimate & S.E. & C.R. & $\mathrm{p}$ \\
\hline trust in independent sources & $\leftarrow$ & general trust & -0.13 & 0.05 & -2.92 & 0.00 \\
trust in food chain actors & $\leftarrow$ & general trust & -0.09 & 0.04 & -2.54 & 0.01 \\
risk & $\leftarrow$ & quality consciousness & -0.20 & 0.09 & -2.21 & 0.03 \\
risk & $\leftarrow$ & trust in independent sources & -0.14 & 0.06 & -2.51 & 0.01 \\
risk & $\leftarrow$ & trust in food chain actors & -0.28 & 0.07 & -3.78 & $* * *$ \\
risk & $\leftarrow$ & trust in media & 0.18 & 0.10 & 1.90 & 0.06 \\
risk & $\leftarrow$ & knowledge of risk & 0.46 & 0.06 & 7.82 & $* * *$ \\
risk & $\leftarrow$ & trust in other media & -0.34 & 0.10 & -3.60 & $* * *$ \\
\hline
\end{tabular}

\section{Discussion and Conclusions}

The proposed models shed some light on the role of risk and trust in determining the purchasing behaviour with respect to a standard food like chicken. Besides the overwhelming impact of taste, possibly related to the importance of culinary practices for Italian, risk perception appear to be another important determinant of the global attitude toward buying chicken even in a day to day context. Thus factors affecting risks play a crucial although indirect role in explaining attitudes and related intentions to behave. Notably, the higher the social trust, the lower the perceived risks from eating chicken. However, while trust in food chain actors and independent actors is correlated with lower risk perception, trust in media seems to play a more ambiguous role in Italy.

The results of this modelling exercise emphasize that building a reputation of trustworthiness is a prerequisite for food chain and independent actors to spread confidence among consumers. On the other side, the choice of information formats and the type of media should be carefully considered in designing a communication campaign.

Further research is needed on these issues in order to investigate whether these patterns of relationship are stable with respect to other behavioural contexts. In particular the role of trust and risk should be reassessed in presence of a food scare in order to compare attitude formation process in "normal" and in "exceptional" contexts.

\section{References}

Ajzen, I., and Fishbein, M. (1980), Understanding Attitudes and Predicting Social Behaviour. Englewood Cliffs, NJ: Prentice-Hall International.

Ajzen, I. (1991), "The theory of planned behaviour", Organisational Behaviour and Human Decision Processes 50 (2): 179-211. 
Bredahl, L., Grunert, K.G., and Frewer, L.J., (1998). "Consumer Attitudes and Decision Making with Regard to Genetically Engineered Food Products - A Review of the Literature and a Presentation of Models for Future Research", Journal of Consumer Policy 21: 251-77.

Bredahl, L., (2000), "Determinants of Consumer Attitudes and Purchase Intentions with Regard to Genetically Modified Foods - Results of a Cross-National Survey", MAPP Working Paper n. 69,

The Aarhus School of Business. Available at: www.mapp.asb.dk/WPpdf/wp69.pdf.

Browne, M.W., and Cudeck, R., (1993), “Alternative Ways of Assessing Model Fit”. In K.A. Bollen and J.S. Long (eds.), Testing structural equation models. London: Sage.

Brunsø, K., Fjord, T.A., and Grunert, K.G., (2002), "Consumers' Food Choice and Quality Perception", MAPP Working Paper no. 77, The Aarhus School of Business. Available at:

www.mapp.asb.dk/WPpdf/wp77.pdf

Buhr, B.L., Hayes, D.J., Shogren, J.F., and Kliebenstein J.B., (1993), "Valuing Ambiguity: the Case of Genetically Engineered Growth Enhancers", Journal of Agricultural and Resource Economics, $18,(2): 175-84$.

Comrey, A.L., and Lee, H.B., (1992), A First Course in Factor Analysis, 2nd ed.. Hillsdale, NJ: Lawrence Erlbaum Associates.

Frewer, L.J., Howard, C., Hedderley D., and Shepherd R., (1996), "What Determines Trust in Information About Food Related Risks? Underlying Psychological Constructs", Risk Analysis 16 (4): 473-86.

Hair, J., Anderson, R., Tatham, T., and Black, W., (1998), Multivariate Data Analysis. Englewood Cliffs, NJ: Prentice Hall.

Hoogland, J.J., and Boomsma, A., (1998), "Robustness Studies in Covariance Structure Modelling", Sociological Methods and Research 26: 329-67.

Kasperson Kasperson, R.E., Renn, O., Slovic, P., Brown, H.S., Hemel, J., Oble, J., Kasperson, J., and Ratick, S., (1988), “The Social Amplification of Risk: A Conceptual Framework”, Risk Analysis 8 (2): 177-87.

Maruyama, G.M., (1998), Basics of Structural Equation Modelling. London: Sage Publications Ltd. Mazzocchi, M., Traill, W.B. and Lobb, A.E. Modelling trust in food safety information and risk within the Theory of Planned Behaviour. In: Trust Working Paper, No. 28, Firenze, Italy, 2004.

McEachern, M.G., and Schröder, M.J.A., (2004), "Integrating the Voice of the Consumer Within the Value Chain: A Focus on Value-Based Labelling Communications in the Fresh-Meat Sector", Journal of Consumer Marketing 21 (7): 497-509.

Pierro, A., Mannetti, L., and Livi, S., (2003), "Self Identity and the Theory of Planned Behaviour in the Prediction of Health Behavior and Leisure Activity", Self and Identity 2 (1): 47-60.

Shaw, D., and Shiu, E., (2002), "The Role of Ethical Obligation and Self-Identity in Ethical Consumer Choice”, International Journal of Consumer Studies 26 (2): 109-16.

Siegrist, M., and Cvetkovich, G., (2000), "Perception of Hazards: The Role of Social Trust and Knowledge", Risk Analysis 20 (5): 713-19.

Siegrist, M., Earle, T.C., and Gutscher, H., (2003), "Test of Trust and Confidence Model in the Applied Context of Electromagnetic Field (EMF) Risks", Risk Analysis 23 (4): 705-16.

Siegrist. M., Cvetkovich. G.. and Roth. C.. (2000), "Salient Value Similarity, Social Trust, and Risk/Benefit Perception", Risk Analysis 20 (3): 353-62.

Slovic, P., (1992). "Perceptions of Risk: Reflections on the Psychometric Paradigm". In Krimsky, S., and Golding, D., (eds.), Social Theories of Risk. Westport: Praeger. 
Sjöberg, L., (1999a), “The Psychometric Paradigm Revisited”, Royal Statistical Society Conference, Warwick, July 12-15. Available at: http:/www.dynam-it.com/riskpercom/pdf/hege.pdf.

Sjöberg, L., (1999b), "Specifying Factors in Radiation Risk Perception”, Center for Risk Research, Stockholm School of Economics. Available at: http:/www.dynam-it.com/riskpercom/pdf/sjp99.pdf. Steenkamp, J.B.E.M., (1989), Product Quality: An Investigation Into the Concept and How It Is Perceived By Consumers. Assen/Maastricht: van Gorsum.

Viklund, M.J., (2003), "Trust and Risk Perception in Western Europe: A Cross National Study", Risk Analysis 23 (4): 727-38.

Ullman, J.B., (2001), "Structural Equation Modelling”. In Tabachnik, B.G., and Fidell, L.S., (eds.), Using Multivariate Statistics, 4th ed. Needham Heights, MA: Pearson Education Company. 